\title{
Prevention of eating disorders: current evidence-base for dissonance-based programmes and future directions
}

\author{
Antonios Dakanalis $^{1}$ (]) $\cdot$ Massimo Clerici $^{1} \cdot$ Eric Stice $^{2}$
}

Received: 16 April 2019 / Accepted: 21 May 2019 / Published online: 30 May 2019

(c) Springer Nature Switzerland AG 2019

\section{Introduction}

Representative data from the USA, Europe and Australia show that around $13 \%$ of females experience a threshold or sub-threshold eating disorder (ED) by young adulthood, which are marked by chronicity, relapse, emotional distress, functional impairment and risk of future obesity, mood, anxiety and substance use disorders, suicide and mortality [1-5]. It is critical that EDs, which show significant and prolonged medical and psychosocial morbidity and stronger relations to functional impairment, suicide attempts and mortality than other psychiatric conditions (comprising mood disorders and schizophrenia), carry high healthcare costs and family burden and are one of the highest-ranking causes of mental health disability [6-12], are successfully fought. Yet over $80 \%$ of ED cases never receive treatment [2, $3]$ and existing treatments only result in lasting ED symptom remission for half or less patients [13]. Thus, a top public health and research priority is to design and broadly implement efficacious ED prevention programmes. These may be effective for EDs whose peak risk period for onset is around ages 16-19 [1, 2, 4], implying that broad implantation of efficacious ED prevention programmes during adolescence could decrease the population prevalence of EDs.

At the turn of the millennium, the state of the science on the prevention of EDs was severely inadequate. The roundtable discussion on the topic convened by the National Institute of Mental Health (USA) [14] highlighted that no prevention programmes had produced meaningful reductions in ED

This article is part of topical collection on Personality and eating and weight disorders.

Antonios Dakanalis

antonios.dakanalis@unimib.it

1 Department of Medicine and Surgery, University of MilanoBicocca, Via Cadore 48, 20900 Monza, Italy

2 Oregon Research Institute, 1776 Millrace Drive, Eugene, OR 97403, USA symptomatology or future ED onset, two crucial outcomes for ED prevention. Since then, the field of ED prevention has made significant strides in successfully translating basic ED risk factor research into efficacious interventions able to reduce ED risk factors and symptomatology and future onset of EDs. This Editorial aims at briefly documenting the aforementioned progress focusing on an intervention model, i.e. the dissonance-based ED prevention approach which, according to recent meta-analytic evidence, produces the largest intervention effects compared to any other type of extant selective (e.g. targeting high-risk people) or indicated (e.g. targeting people who exhibit symptoms, but do not meet ED diagnostic criteria) prevention programmes [15]. Further, this is the only ED prevention approach that meets the American Psychological Association's [16] designation as an efficacious intervention, meaning that it has been found to (a) yield positive effects that have been replicated by independent labs/researchers and (b) significantly outperform active and credible alternative interventions in multiple randomized controlled trials. In addition to increasing awareness in the scientific community and community stakeholders on the empirical evidence base for dissonancebased ED prevention programmes [including basic ED risk factor research underpinning the development of these programmes and rigour tests on the intervention (cognitivedissonance) theory underlying them], this Editorial offers several important research directions, particularly in areas in which queries remain open or we see room for improvement.

\section{Empirical evidence base for dissonance-based ED prevention programmes}

Several malleable sociocultural, behavioural and attitudinal risk factors for EDs (e.g. overeating, pursuit of the thin body ideal, self-objectification and body dissatisfaction) have been detected $[2,17]$, implying that prevention of these pernicious 
psychiatric disorders could be viable. Although dozens of ED prevention programmes have been designed and tested [15, 18-23], only three have decreased ED symptom composite measures [24-26] and/or future onset of EDs [25-27]. As noted, the most empirical support has accumulated for dissonance-based ED prevention programmes, often referred to as the Body Project, which has included numerous randomized (efficacy, effectiveness, and comparative) trials and rigorous tests of the intervention theory carried out by multiple, independent research labs/teams (summarized below). In the Body Project, adolescent girls and young women voluntarily critique the thin body ideal in behavioural, written and verbal exercises, theoretically generating dissonance that causes reduced pursuit of this ultra-slim, unrealistic and unattainable body ideal because individuals align their attitudes with their publicly displayed behaviours [28]. This prevention approach is based on the social psychological principle of cognitive-dissonance theory [29], which holds that people are motivated to maintain consistency between their attitudes and behaviours, and when people engage in behaviours that are inconsistent with their attitudes, they experience psychological discomfort that prompts them to align their attitude with their behaviour. For example, in the Body Project, participants complete role-plays in which they talk facilitators out of pursuing the ultra-slim body ideal, write a letter to a younger self on how to avoid concerns and body image problems, engage in body activism acts that challenge this unrealistic ideal and verbally generate costs associated with pursuing this ideal in response to Socratic questions. For interested readers the intervention (i.e. Body Project) script is available online at: www.bodyprojectsupp ort.org.

According to the dual pathway model of EDs (for a detailed description, see [30]), reduced subscription to the thin body ideal (often referred to as thin-ideal internalization [31]) should reduce body dissatisfaction, unhealthy weight control behaviours, negative affect, ED symptoms, and the risk for future onset of EDs. In support, basic ED risk factor research showed that elevated thin-ideal internalization, body dissatisfaction, negative affect, and dieting predict future onset of any DSM-5 ED (see [2] and the references therein)]. Research has also revealed that thin-ideal internalization typically emerges before body dissatisfaction, which emerges before negative affect and dieting, which typically precede onset of an ED, for those people who eventually display ED onset [30]. Thus, thin-ideal internalization is at the headwaters of an etiologic cascade of risk factors that give rise to ED onset and the Body Project that targets this variable should reduce onset of ED symptoms/syndromes, as well as adverse downstream risk factors such as body dissatisfaction and negative affect. Accumulated empirical evidence summarized below supports this notion.
Efficacy trials conducted by Stice and colleagues (e.g. $[25,28,32,33])$ have shown that the Body Project yielded greater reductions in ED risk factors (i.e. thin-ideal internalization, dieting, negative affect and body dissatisfaction) and symptoms in female samples with body image problems/concerns relative to both credible alternative interventions and assessment-only control conditions, with several effects enduring through 3-year follow-ups. Similar effects have emerged in several efficacy trials carried out by independent research teams (e.g. [34-36]), though not all of these trials targeted females with body image problems/ concerns. Moreover, the Body Project decreased ED symptomatology and electrocardiogram-assessed cardiac risk indices among females with sub-clinical and clinical EDs [37], which is relevant since cardiac problems are among the leading mortality causes among such people. Hence, the Body Project has demonstrated efficacy when implemented (a) universally to females who were not screened for body image problems, (b) selectively to females with body image concerns, and (c) in an indicated fashion to females with ED symptomatology. In addition to the aforementioned efficacy trials examining whether preventive interventions produce effects under carefully controlled experimental conditions, multiple independent effectiveness trials confirmed that the Body Project yields greater reductions in ED risk factors and symptoms compared with educational video control conditions and educational brochure, when college counsellors or undergraduate peer educators deliver the intervention under "real world" and ecologically valid conditions, with several effects enduring through 3-year follow-ups (e.g. [38-41]).

The evidence that the Body Project has yielded positive and reproducible effects across independent trials is notable given the recently evidenced "crisis" of replication in the fields of psychology and other sciences [42]. Further, the fact that the Body Project outperforms credible alternative interventions implies that the intervention effects are not simply due to demand characteristics, expectancies or non-specific effects inherent to randomized trials. As noted, a recent meta-analytic review by Watson and colleagues [15] showed that, averaging across all randomized trials, dissonance-based ED prevention programmes produced the largest reductions in ED symptomatology compared to any other type of extant selective or indicated prevention programmes, with an average $d=0.30$ when compared with non-specific control conditions and an average $d=1.06$ when compared with assessment-only control conditions. Perhaps most critically, the Body Project has also been found to significantly reduce future onset of threshold and sub-threshold EDs among participants free of any ED at baseline. Specifically, the Body Project has yielded a $60 \%$ reduction in future ED onset over 3-year follow-up relative to assessment-only controls [25] and a 57\% reduction in future ED onset over 3 -year follow-up relative to educational video controls [43]. 
In addition, there is trial evidence that virtual delivery of the Body Project produced a $73 \%$ reduction in future ED onset over 2-year follow-up relative to an expressive writing control [44], implying that this novel implementation approach could dramatically extend the reach of the dissonance-based ED prevention programmes.

In support of the intervention theory, decreases in thinideal internalization mediated the effects of the Body Project on ED symptom reduction (e.g. [45]). Consistent with the thesis that dissonance induction contributes to intervention effects, people assigned to versions of the Body Project designed to maximize dissonance reported greater ED symptom reduction that those assigned to versions of the Body Project designed to minimize dissonance but with the same intervention content (e.g. [46]). Further, the Body Project yielded larger effects for females with initial elevated thin-ideal internalization, in line with the notion that they should experience the highest dissonance [47]. Completing the Body Project also offset the ED risk conveyed by thin-ideal internalization [48]; females with this potent ED risk factor who completed the Body Project displayed an ED incidence of $0 \%$ over a 3-year follow-up versus $50 \%$ for assessment-only controls and $18 \%$ for those who completed alternative interventions. Completion of the Body Project also eliminated the negative effects of exposure to thin models on young females' body dissatisfaction [34]. Finally, there is objective biological evidence that the Body Project reduced functional magnetic resonance imagingassessed reward region (caudate) response to images of thin models, indicating that this prevention approach alters neural response to thin-ideal stimuli [49], which theoretically play a key role in the development of body dissatisfaction and EDs [50,51], and implying that females who complete it may not perceive the thin body ideal as a desirable goal.

\section{Conclusions and future directions}

Over the past 2 decades, the ED field has made significant strides in successfully translating basic ED risk factor research into preventive interventions with documented effectiveness and efficacy in reducing ED risk factors and symptomatology, as well as future ED onset (i.e. a true prevention effect) in multiple randomized controlled trial. As noted, the staunchest and most empirical support has been garnered for dissonance-based ED prevention programmes, also known as the Body Project, the only intervention that has produced positive and replicated effects in multiple American trials, and significantly larger intervention effects than several credible alternative interventions through 3-year follow-ups. Consistent with the highlighted urgent need to broadly implement efficacious ED prevention programmes in Europe [2, 8], it is important that large-scale randomized controlled trials test the hypothesis that the Body Project reduces future onset of women's EDs in Europe, translating principles that have proven effective in another (i.e. American) culture and addressing a major public health problem. It would also be useful for future research to use follow-up periods longer than 3 years (the longest follow-up to date), and other rigorous research methods such as comparing the Body Project with credible alternative control conditions and other ED prevention programmes with a broad evidence base (see $[15,23])$ and use of fidelity checks, blinded interview assessment to assess EDs and objective biological outcomes (immune to the demand characteristics inherent in randomized controlled trials).

It is worth noting that there has been variation in intervention effects, with some randomized controlled trials showing that dissonance-based ED prevention programmes yield small effects (e.g. [41]) and other showing that that they yield large effects on ED outcomes (e.g. [52]). Elucidation of features related to larger effects is important, as it can inform implementation of optimally effective versions of these ED prevention programmes [53]. As such, it would be beneficial to carry out randomized experiments that manipulate the moderators that received the strongest support in a just published meta-analysis conducted by Stice and colleagues [53] (i.e. the number of facilitators and training hours, the number of dissonance-based activities in the ED prevention programme, and whether supervision is provided) to corroborate that they are causally associated with larger intervention effects. For example, a trial comparison of the Body Project when implemented by clinicians versus peer educators showed that peer-led groups yielded significantly greater reductions in future ED onset over a 3-year follow-up compared to clinician-led groups [43]. It would be beneficial to get experimental support for the thesis that combining the mentioned moderators should yield larger intervention effects [53]. It would also be beneficial to detect the types of females who subsequently develop an ED despite completing the Body Project so that alternative interventions can be designed for such females. Despite the encouraging evidence-base for the Body Project, we feel it is important to evaluate alterations that might enhance its efficacy, such as adding (e.g. dissonance-based) intervention elements that focus on reducing self-objectification (i.e. thinking and monitoring the body's outward appearance from an external observer's perspective [54-56]), as this extremely potent and newly emerged risk factor for DSM-5 ED onset [2], which fits within the well-supported dual pathway model of EDs (see $[2,56]$ for details) underpinning the development of the Body Project, is not addressed in its current version. Another direction would be to design additional ED prevention programmes that target distinct ED risk factors (e.g. impaired psychosocial functioning) [17], if we are to achieve the goal of decreasing the population prevalence of female EDs. 
Given accumulated empirical evidence on males, body image disturbance and EDs [4, 57-64], scholars have recently examined the efficacy of an adapted version of the Body Project for males [65]. Results showed that young men with body image concerns/problems randomized to this adapted version of the Body Project reported meaningful reductions in ED risk factors (e.g. body-ideal internalization, dieting and body dissatisfaction) and symptomatology, with the effects persisting through 1-month follow-up year relative to waitlist [65]. Despite these promising results, replication trials conducted by independent groups are needed. We think it would also be useful to examine this adapted version of the Body Project for males against active control conditions and test whether it reduces future onset of threshold/ sub-threshold EDs [61].

Finally, it would be beneficial to implement efficacious prevention programmes that affect multiple major public health problems, such as obesity and EDs [66-71], which appear to share certain risk factors (e.g. negative affect, reported caloric restriction, low self-esteem and body dissatisfaction) [72-80]. Although several prevention programmes have sought to reduce future onset of both EDs and obesity (e.g. [68]), only the Healthy Weight programme has successfully affected both outcomes (see below). In Healthy Weight, young people with body image concerns/problems make small, permanent healthy changes to exercise and dietary intake that bring energy intake and expenditure into balance, which should decrease weight gain and risk for EDs [81]. In support, randomized efficacy trials showed that the Healthy Weight programme decreased weight increases and ED symptoms and reduced obesity onset and ED onset relative to assessment-only control conditions and alternative interventions through 3-year follow-up (see [81, 82] for details). Perhaps most critically, a recent trial found that adding activities designed to create cognitive dissonance regarding overeating, a sedentary lifestyle and excess body fat to the Healthy Weight dual obesity and ED prevention programme improved efficacy [83]; the new dissonancebased Project Health prevention programme produced a $40 \%$ reduction in overweight/obesity onset relative to the Healthy Weight intervention and a $42 \%$ reduction in overweight/obesity onset relative to an educational video control condition over 2-year follow-up, and both Project Health and Healthy Weight interventions produced a $62 \%$ reduction in future ED onset over 2-year follow-up [83]. Despite these encouraging results, replication trials conducted by independent groups are needed. In addition, it would be useful for future research to test the potential of an Internet (and cost-effective) version of the Healthy Weight and new dissonance-based Project Health prevention programmes to reduce future ED and obesity onset. Finally, there is recent trial evidence that an Internet version of the noted Body Project showed a significant reduction in ED symptoms and body mass index relative to educational video control conditions and educational brochure through a 1-year follow-up [84]. Given accumulated evidence [25, 28, 32-41] that the Body Project yields greater reductions in factors that greatly increase the likelihood of both obesity and EDs (i.e. negative affect and body dissatisfaction) [72-80], it would be useful for future research to test the potential of this Internet version of the Body Project to reduce future ED and obesity onset. With continued research, we hope it will be possible to broadly implement programmes that prevent both excess weight gain (i.e. overweight/obesity) and EDs.

\section{Compliance with ethical standards}

Conflict of interest Preparation of this article was supported by research grants from the National Institutes of Health (MH/DK061957, MH070699, MH086582, MH097720 and MH111782), European Commission (745948), National (CONV-0036) and International Charitable Foundations (O/RG 2019-WT3748), HE/Research Institutions (ATESP0580, ATESP0601, ATE0204, ATE0203 and ATE0573) and the Italian Ministry of Education, Universities and Research (PRIN-201597WTTM). The authors state that there is no conflict of interest.

Ethical approval This article does not contain any studies with human participants or animals performed by any of the authors.

Informed consent For this type of study, formal consent is not required.

\section{References}

1. Stice E, Marti CN, Rohde P (2013) Prevalence, incidence, impairment, and course of the proposed DSM-5 eating disorder diagnoses in an 8-year prospective community study of young women. J Abnorm Psychol 122:445-457. https://doi.org/10.1037/a0030679

2. Dakanalis A, Clerici M, Bartoli F, Caslini M, Crocamo C, Riva G, Carrà G (2017) Risk and maintenance factors for young women's DSM-5 eating disorders. Arch Womens Mental Health 20(6):721731. https://doi.org/10.1007/s00737-017-0761-6

3. Swanson SA, Crow SJ, le Grange D, Swendsen J, Merikangas KR (2011) Prevalence and correlates of eating disorders in adolescents: results from the national comorbidity survey replication adolescent supplement. Arch Gen Psychiatry 68(7):714-723. https ://doi.org/10.1001/archgenpsychiatry.2011.22

4. Allen KL, Byrne SM, Oddy WH, Crosby RD (2013) DSM-IV-TR and DSM-5 eating disorders in adolescents: prevalence, stability, and psychosocial correlates in a population-based sample of male and female adolescents. J Abnorm Psychol 122:720-732. https:// doi.org/10.1037/a0034004

5. Arcelus J, Mitchell AJ, Wales J, Nielsen S (2011) Mortality rates in patients with anorexia nervosa and other eating disorders. A meta-analysis of 36 studies. Arch Gen Psychiatry 68(7):724-731. https://doi.org/10.1001/archgenpsychiatry.2011.74

6. Crow S, Smiley N (2010) Costs and cost-effectiveness in eating disorders. In: Agras WS (ed) The Oxford handbook of eating disorders Oxford, 1st edn. Oxford University Press, Oxford, pp 480-485 
7. Dakanalis A, Clerici M, Riva G, Carrà G (2017) Testing the DSM-5 severity indicator for bulimia nervosa in a treatmentseeking sample. Eat Weight Disord 22(1):161-167. https://doi. org/10.1007/s40519-016-0324-2

8. van Furth EF, van der Meer A, Cowan K (2016) Top 10 research priorities for eating disorders. Lancet Psychiatry 3(8):706-707. https://doi.org/10.1016/S2215-0366(16)30147-X

9. Dakanalis A, Colmegna F, Riva G, Clerici M (2017) Validity and utility of the DSM-5 severity specifier for binge-eating disorder. Int J Eat Disord 50(8):917-923. https://doi.org/10.1002/eat.22696

10. Ágh T, Kovács G, Supina D, Pawaskar M, Herman BK, Vokó Z, Sheehan DV (2016) A systematic review of the health-related quality of life and economic burdens of anorexia nervosa, bulimia nervosa, and binge eating disorder. Eat Weight Disord 21(3):353364. https://doi.org/10.1007/s40519-016-0264-X

11. Dakanalis A, Timko A, Colmegna F, Riva G, Clerici M (2018) Evaluation of the DSM-5 severity ratings for anorexia nervosa in a clinical sample. Psychiatry Res 262:124-128. https://doi. org/10.1016/j.psychres.2018.02.009

12. Schmidt U, Adan R, Böhm I, Campbell IC, Dingemans A, Ehrlich S, Elzakkers I, Favaro A, Giel K, Harrison A, Himmerich H, Hoek HW, Herpertz-Dahlmann B, Kas MJ, Seitz J, Smeets P, Sternheim L, Tenconi E, van Elburg A, van Furth E, Zipfel S (2016) Eating disorders: the big issue. Lancet Psychiatry 3(4):313-315. https:// doi.org/10.1016/S2215-0366(16)00081-X

13. Hay P (2013) A systematic review of evidence for psychological treatments in eating disorders: 2005-2012. Int J Eat Disord 46(5):462-469. https://doi.org/10.1002/eat.22103

14. Pearson J, Goldklang D, Striegel-Moore RH (2002) Prevention of eating disorders: challenges and opportunities. Int J Eat Disord 31(3):233-239. https://doi.org/10.1002/eat.10014

15. Watson HJ, Joyce T, French E, Willan V, Kane RT, Tanner-Smith EE, McCormack J, Dawkins H, Hoiles KJ, Egan SJ (2016) Prevention of eating disorders: a systematic review of randomized, controlled trials. Int J Eat Disord 49(9):833-862. https://doi. org/10.1002/eat.22577

16. American Psychological Association, Task Force on Psychological Intervention Guidelines (1995) Template for developing guidelines: interventions for mental disorders and psychological aspects of physical disorders, 1st edn. American Psychological Association, Washington DC

17. Stice E, Gau J, Rohde P, Shaw H (2017) Risk factors that predict future onset of each DSM-5 eating disorder: predictive specificity in high-risk adolescent females. J Abnorm Psychol 126:38-51. https://doi.org/10.1037/abn0000219

18. Völker U, Jacobi C, Barr Taylor C (2011) Adaptation and evaluation of an internet-based prevention program for eating disorders in a sample of women with subclinical eating disorder symptoms: a pilot study. Eat Weight Disord 16(4):e270-e273. https://doi. org/10.1007/BF03327471

19. Pokrajac-Bulian A, Zivcić-Becirević I, Calugi S, Dalle Grave R (2006) School prevention program for eating disorders in Croatia: a controlled study with six months of follow-up. Eat Weight Disord 11(4):171-178. https://doi.org/10.1007/BF03327568

20. Lee GY, Park EJ, Kim YR, Kwag KH, Park JH, An SH, Lee JH, Sim JH, Treasure J (2018) Feasibility and acceptability of a prevention program for eating disorders (Me, You and Us) adapted for young adolescents in Korea. Eat Weight Disord 23(5):673683. https://doi.org/10.1007/s40519-017-0436-3

21. Dunker KL, Philippi ST, Ikeda JP (2010) Interactive Brazilian program to prevent eating disorders behaviors: a pilot study. Eat Weight Disord 15(4):e270-e274. https://doi.org/10.1007/BF033 25309

22. Ponce Escoto, de León MC, Mancilla Díaz JM, Camacho Ruiz EJ (2008) A pilot study of the clinical and statistical significance of a program to reduce eating disorder risk factors in children.
Eat Weight Disord 13(3):111-118. https://doi.org/10.1007/BF033 27611

23. Ciao AC, Loth K, Neumark-Sztainer D (2014) Preventing eating disorder pathology: common and unique features of successful eating disorders prevention programs. Curr Psychiatry Rep 16(7):453. https://doi.org/10.1007/s11920-014-0453-0

24. Atkinson M, Wade T (2016) Does mindfulness have potential in eating disorder prevention? A preliminary controlled trial with young adult women. Early Interv Psychiatry 10(3):234-245. https ://doi.org/10.1111/eip.12160

25. Stice E, Marti CN, Spoor S, Presnell K, Shaw H (2008) Dissonance and healthy weight eating disorder prevention programs: long-term effects from a randomized efficacy trial. J Consult Clin Psychol 76:329-340. https://doi.org/10.1037/0022-006X.76.2.329

26. Stice E, Rohde P, Shaw H, Marti CN (2013) Efficacy trial of a selective prevention program targeting both eating disorders and obesity among female college students: 1- and 2-year follow-up effects. J Consult Clin Psychol 81:183-189. https://doi. org/10.1037/a0031235

27. Martinsen M, Bahr R, Børresen R, Holme I, Pensgaard AM, Sundgot-Borgen J (2014) Preventing eating disorders among young elite athletes: a randomized controlled trial. Med Sci Sports Exerc 46:435-447. https://doi.org/10.1249/MSS.0b013e3182a702fc

28. Stice E, Mazotti L, Weibel D, Agras WS (2000) Dissonance prevention program decreases thin-ideal internalization, body dissatisfaction, dieting, negative affect, and bulimic symptoms: a preliminary experiment. Int J Eat Disord 27:206-217. https ://doi.org/10.1002/(SICI)1098-108X(200003)27:2\%3c206 :AID-EAT9\%3e3.0.CO;2-D

29. Festinger L (1957) A theory of cognitive dissonance, 1st edn. Stanford University Press, Stanford

30. Stice E, Van Ryzin M (2019) A prospective test of the temporal sequencing of risk factor emergence in the dual pathway model of eating disorders. J Abnorm Psychol 128:119-128. https://doi. org/10.1037/abn0000400

31. Schaefer LM, Burke NL, Thompson JK (2018) Thin-ideal internalization: how much is too much? Eat Weight Disord. https://doi. org/10.1007/s40519-018-0498-x

32. Stice E, Chase A, Stormer S, Appel A (2001) A randomized trial of a dissonance-based eating disorder prevention program. Int $\mathrm{J}$ Eat Disord 29:247-262. https://doi.org/10.1002/eat.1016

33. Stice E, Shaw H, Burton E, Wade E (2006) Dissonance and healthy weight eating disorder prevention programs: a randomized efficacy trial. J Consult Clin Psychol 74:263-275. https://doi. org/10.1037/0022-006X.74.2.263

34. Halliwell E, Diedrichs P (2014) Testing a dissonance body image intervention among young girls. Health Psychol 33:201-204. https ://doi.org/10.1037/a0032585

35. Matusek JA, Wendt SJ, Wiseman CV (2004) Dissonance thinideal and didactic healthy behavior eating disorder prevention programs: results from a controlled trial. Int J Eat Disord 36:376-388. https://doi.org/10.1002/eat.20059

36. Mitchell KS, Mazzeo SE, Rausch SM, Cooke KL (2007) Innovative interventions for disordered eating: evaluating dissonancebased and yoga interventions. Int J Eat Disord 40:120-128. https ://doi.org/10.1002/eat.20282

37. Green M, Willis M, Fernandez-Kong K, Reyes S, Linkhart R, Johnson M, Thorne T, Kroska E, Woodward H, Lindberg J (2017) Dissonance-based eating disorder program reduces cardiac risk: a preliminary trial. Health Psychol 36:346-355. https://doi. org/10.1037/hea0000438

38. Stice E, Rohde P, Butryn ML, Shaw H, Marti CN (2015) Effectiveness trial of a selective dissonance-based eating disorder prevention program with female college students: effects at 2-and 3-year follow-up. Behav Res Ther 71:20-26. https://doi.org/10.1016/j. brat.2015.05.012 
39. Stice E, Rohde P, Shaw H, Gau J (2011) An effectiveness trial of a selected dissonance-based eating disorder prevention program for female high school students: long-term effects. J Consult Clin Psychol 79:500-508. https://doi.org/10.1037/a0024351

40. Halliwell E, Jarman H, McNamara A, Risdon H, Jankowski G (2015) Dissemination of evidence-based body image interventions: a pilot study into the effectiveness of using undergraduate students as interventionists in secondary schools. Body Image 14:1-4. https://doi.org/10.1016/j.bodyim.2015.02.002

41. Stice E, Rohde P, Durant S, Shaw H, Wade E (2013) Effectiveness of peer-led dissonance eating disorder prevention groups: results from two randomized trials. Behav Res Ther 51:197206. https://doi.org/10.1016/j.brat.2013.01.004

42. Ioannidis JPA, Munafò MR, Fusar-Poli P, Nosek BA, David SP (2014) Publication and other reporting biases in cognitive sciences: detection, prevalence and prevention. Trends Cogn Sci 18(5):235-241. https://doi.org/10.1016/j.tics.2014.02.010

43. Stice E, Rohde P, Shaw H, Gau J (2019) Clinician-led, peerled, and Internet-delivered dissonance-based eating disorder prevention programs: effects through 3-year follow-up. Paper presented at the Universidad Iberoamericana, Mexico City, 8 April 2019

44. Ghaderi A, Andersson A, Stice E, Persson JE, Allzén E (2019) Prevention of eating disorders: long-term follow up of dissonancebased intervention delivered via virtual groups. Paper presented at the 14th International London Eating Disorders Conference, London, 20-22 March 2019

45. Seidel A, Presnell K, Rosenfield D (2009) Mediators in the dissonance eating disorder prevention program. Behav Res Ther 47:645-653. https://doi.org/10.1016/j.brat.2009.04.007

46. Green M, Scott N, Diyankova I, Gasser C, Pederson E (2005) Eating disorder prevention: an experimental comparison of high-level dissonance, low-level dissonance, and no-treatment control. Eat Disord 13:157-169. https://doi.org/10.1080/10640260590918955

47. Stice E, Marti N, Shaw H, O'Neil K (2008) General and programspecific moderators of two eating disorder prevention programs. Int J Eat Disord 41:611-617. https://doi.org/10.1002/eat.20524

48. Stice E, Rohde P, Gau J, Shaw H (2012) Effect of a dissonancebased prevention program on risk for eating disorder onset in the context of eating disorder risk factors. Prev Sci 13:129-139. https ://doi.org/10.1007/s11121-011-0251-4

49. Stice E, Yokum S, Waters A (2015) Dissonance-based eating disorder prevention program reduces reward region response to thin models: how actions shape valuation. PLoS One 10(12):e0144530. https://doi.org/10.1371/journal.pone.0144530

50. Lantz EL, Gaspar ME, DiTore R, Piers AD, Schaumberg K (2018) Conceptualizing body dissatisfaction in eating disorders within a self-discrepancy framework: a review of evidence. Eat Weight Disord 23(3):275-291. https://doi.org/10.1007/s4051 9-018-0483-4

51. Schaefer LM, Burke NL, Anderson LM, Thompson JK, Heinberg LJ, Bardone-Cone AM, Neyland MKH, Frederick DA, Anderson DA, Schaumberg K, Nerini A, Stefanile C, Dittmar H, Klump KL, Vercellone AC, Paxton SJ (2018) Comparing internalization of appearance ideals and appearance-related pressures among women from the United States, Italy, England, and Australia. Eat Weight Disord. https://doi.org/10.1007/s40519-018-0544-8

52. Smith A, Petrie T (2008) Reducing the risk of disordered eating among female athletes: a test of alternative interventions. J Appl Sport Psychol 20:392-407. https://doi.org/10.1080/1041320080 2241832

53. Stice E, Marti CN, Shaw H, Rohde P (2019) Meta-analytic review of dissonance-based eating disorder prevention programs: intervention, participant, and facilitator features that predict larger effects. Clin Psycol Rev. https://doi.org/10.1016/j.cpr.2019.04.004
54. Dakanalis A, Zanetti MA, Riva G, Clerici M (2013) Psychosocial moderators of the relationship between body dissatisfaction and symptoms of eating disorders: a look at a sample of young Italian women. Eur Rev Appl Psychol 63(5):323-334. https://doi. org/10.1016/j.erap.2013.08.001

55. Holmes M, Fuller-Tyszkiewicz M, Skouteris H, Broadbent J (2015) Understanding the link between body image and binge eating: a model comparison approach. Eat Weight Disord 20(1):8189. https://doi.org/10.1007/s40519-014-0141-4

56. Dakanalis A, Timko A, Serino S, Riva G, Clerici M, Carrà G (2016) Prospective psychosocial predictors of onset and cessation of eating pathology amongst college women. Eur Eat Disord Rev 24(3):251-256. https://doi.org/10.1002/erv.2433

57. Dakanalis A, Clerici M, Caslini M, Gaudio S, Serino S, Riva G, Carrà G (2016) Predictors of initiation and persistence of recurrent binge eating and inappropriate weight compensatory behaviors in college men. Int J Eat Disord 49(6):581-590. https://doi. org/10.1002/eat.22535

58. Dakanalis A, Carrà G, Timko A, Volpato C, Pla-Sanjuanelo J, Zanetti A, Clerici M, Riva G (2015) Mechanisms of influence of body checking on binge eating. Int J Clin Health Psychol 15(2):93-104. https://doi.org/10.1016/j.ijchp.2015.03.003

59. Dakanalis A, Carrà G, Clerici M, Riva G (2015) Efforts to make clearer the relationship between body dissatisfaction and binge eating. Eat Weight Disord 20(1):145-146. https://doi.org/10.1007/ s40519-014-0152-1

60. Serino S, Dakanalis A, Gaudio S, Carrà G, Cipresso P, Clerici M, Riva G (2015) Out of body, out of space: impaired reference frame processing in eating disorders. Psychiatry Res 230(2):732-734. https://doi.org/10.1016/j.psychres.2015.10.025

61. Dakanalis A, Pla-Sanjuanelo J, Caslini M, Volpato C, Riva G, Clerici M, Carrà G (2016) Predicting onset and maintenance of men's eating disorders. Int J Clin Health Psychol 16(3):247-255. https://doi.org/10.1016/j.ijchp.2016.05.002

62. Dakanalis A, Favagrossa L, Clerici M, Prunas A, Colmegna F, Zanetti MA, Riva G (2015) Body dissatisfaction and eating disorder symptomatology: a latent structural equation modeling analysis of moderating variables in 18-to-28-year-old males. J Psychol 149(1):85-112. https://doi.org/10.1080/00223980.2013.842141

63. Dakanalis A, Timko A, Madeddu F, Volpato C, Clerici M, Riva G, Zanetti AM (2015) Are the male body dissatisfaction and drive for muscularity scales reliable and valid instruments? J Health Psychol 20(1):48-59. https://doi.org/10.1177/135910531349810

64. Dakanalis A, Timko CA, Riva G, Madeddu F, Clerici M, Zanetti MA (2014) A comprehensive examination of the transdiagnostic cognitive behavioral model of eating disorders in males. Eat Behav 15(1):63-67. https://doi.org/10.1016/j.eatbeh.2013.10.003

65. Brown TA, Forney KJ, Pinner D, Keel PK (2017) A randomized controlled trial of the Body Project: more than muscles for men with body dissatisfaction. Int J Eat Disord 50(8):873-883. https ://doi.org/10.1002/eat.22724

66. Neumark-Sztainer D (2009) The interface between the eating disorders and obesity fields: moving toward a model of shared knowledge and collaboration. Eat Weight Disord 14(1):51-58. https://doi.org/10.1007/BF03327795

67. Dakanalis A, Clerici M (2017) The nature of the association between binge-eating severity and metabolic syndrome. Eat Weight Disord 22(3):553-554. https://doi.org/10.1007/s4051 9-017-0386-9

68. Leme ACB, Philippi ST, Thompson D, Nicklas T, Baranowski T (2019) "Healthy Habits, Healthy Girls—Brazil": an obesity prevention program with added focus on eating disorders. Eat Weight Disord 24(1):107-119. https://doi.org/10.1007/s4051 9-018-0510-5

69. Ferrari M (2015) Understanding the feasibility of integrating the eating disorders and obesity fields: the beyond obesity and 
disordered eating in youth (BODY) study. Eat Weight Disord 20(2):257-269. https://doi.org/10.1007/s40519-014-0172-x

70. Dakanalis A, Clerici M (2019) Tackling excess body weight in people with binge eating disorder. Aust N Z J Psychiatry. https:// doi.org/10.1177/0004867419853346

71. Bullivant B, Mitchison D, Skromanis S, Mond J (2019) Elucidating individuals' beliefs about the severity of eating disorders and obesity: implications for public health programs. Eat Weight Disord. https://doi.org/10.1007/s40519-019-00708-6

72. Neumark-Sztainer D, Wall MM, Haines JI, Story MT, Sherwood NE, van den Berg PA (2007) Shared risk and protective factors for overweight and disordered eating in adolescents. Am J Prev Med 33:359-369. https://doi.org/10.1016/j.amepre.2007.07.031

73. Riva G, Gaggioli A, Dakanalis A (2013) From body dissatisfaction to obesity: how virtual reality may improve obesity prevention and treatment in adolescents. Stud Health Technol Inform 184:356-362. https://doi.org/10.3233/978-1-61499-209-7-356

74. Riva G, Serino S, Di Lernia D, Pavone EF, Dakanalis A (2017) Embodied medicine: mens sana in corpore virtuale sano. Front Hum Neurosci 11:120. https://doi.org/10.3389/fnhum.2017.00120

75. Pla-Sanjuanelo J, Ferrer-García M, Gutiérrez-Maldonado J, Riva G, Andreu-Gracia A, Dakanalis A, Fernandez-Aranda F, Forcano L, Ribas-Sabaté J, Riesco N, Rus-Calafell M, Sánchez I, SanchezPlanell L (2015) Identifying specific cues and contexts related to bingeing behavior for the development of effective virtual environments. Appetite 87:81-89. https://doi.org/10.1016/j.appet 2014.12.098

76. Ferrer-García M, Gutiérrez-Maldonado J, Pla-Sanjuanelo J, Vilalta-Abella F, Riva G, Clerici M, Ribas-Sabaté J, AndreuGracia A, Fernandez-Aranda F, Forcano L, Riesco N, Sánchez I, Escandón-Nagel N, Gomez-Tricio O, Tena V, Dakanalis A (2017) A randomised controlled comparison of second-level treatment approaches for treatment-resistant adults with bulimia nervosa and binge eating disorder: assessing the benefits of virtual reality cue exposure therapy. Eur Eat Disord Rev 25(6):479-490. https ://doi.org/10.1002/erv.2538

77. Dakanalis A, Zanetti MA, Clerici M, Madeddu F, Riva G, Caccialanza R (2013) Italian version of the Dutch Eating Behavior
Questionnaire: psychometric proprieties and measurement invariance across sex, BMI-status and age. Appetite 71:187-195. https ://doi.org/10.1016/j.appet.2013.08.010

78. Fairburn CG, Cooper Z, Doll HA, Davies BA (2005) Identifying dieters who will develop an eating disorder: a prospective, population-based study. Am J Psychiatry 162:2249-2255. https ://doi.org/10.1176/appi.ajp.162.12.2249

79. Stice E, Presnell K, Shaw H, Rohde P (2005) Psychological and behavioural risk factors for obesity onset in adolescent girls: a prospective study. J Consult Clin Psychol 73:195-202. https:// doi.org/10.1037/0022-006X.73.2.195

80. Riva G, Gaudio S, Dakanalis A (2014) I'm in a virtual body: a locked allocentric memory may impair the experience of the body in both obesity and anorexia nervosa. Eat Weight Disord 19(1):133-134. https://doi.org/10.1007/s40519-013-0066-3

81. Stice E, Marti CN, Spoor S, Presnell K, Shaw H (2008) Dissonance and healthy weight eating disorder prevention programs: longterm effects from a randomized efficacy trial. J Consult Clin Psychol 76(2):329-340. https://doi.org/10.1037/0022-006X.76.2.329

82. Stice E, Shaw H, Burton E, Wade E (2006) Dissonance and healthy weight eating disorder prevention programs: a randomized efficacy trial. J Consult Clin Psychol 74(2):263-275. https://doi. org/10.1037/0022-006X.74.2.263

83. Stice E, Rohde P, Shaw H, Gau J (2018) An experimental therapeutics test of whether adding dissonance-induction activities improves the effectiveness of a selected obesity and eating disorder prevention program. Int J Obes 42(3):462-468. https://doi. org/10.1038/ijo.2017.251

84. Stice E, Rohde P, Durant S, Shaw H (2012) A prototype internet dissonance- based eating disorder prevention program for young women with body image concerns. J Consult Clin Psychol 80:907-916. https://doi.org/10.1037/a0028016

Publisher's Note Springer Nature remains neutral with regard to jurisdictional claims in published maps and institutional affiliations. 